\title{
Guidance of Regenerating Motor Axons in Larval and Juvenile Bullfrogs
}

\author{
Matt T. Lee ${ }^{a}$ and Paul B. Farel \\ Department of Physiology, School of Medicine, University of North Carolina, Chapel Hill, North Carolina 27599
}

\begin{abstract}
The segmental distribution of regenerating bullfrog motor axons was mapped in advanced tadpoles and juvenile trogs by stimulating selected muscle nerves and recording from the distal ends of the 3 lumbar ventral roots (VRs) that innervate the hindlimb. When motoneurons were axotomized by VR transection, they reestablished their original innervation fields, rarely, if ever, growing beyond the territory normally supplied by their spinal segment. However, when motoneurons were axotomized in the spinal nerves at the level of the hindlimb plexus, some of them regenerated into limb nerves that lay outside the axons' normal segmental boundaries, and many regenerated into the medial femoral cutaneous nerve, a pathway normally limited to sensory axons. These observations suggest that the ultimate destinations of regenerating axons are largely determined by structures the axons encounter as they penetrate the distal nerve stumps. Thus, axons regenerating from a severed VR grow into that root's own distal stump and reinnervate the hindlimb in a manner that is segmentally appropriate; axons transected near the plexus have access to the pathways of sensory, as well as motor, axons in all 3 lumbar segments, and establish innervation fields that are inappropriate for their segment of origin and their motor function.
\end{abstract}

Axons regenerating in the vertebrate peripheral nervous system appear to be guided by structures remaining within the nerve stump distal to the site of injury. The existence of such guidance is suggested by the fact that the branching pattern of a regenerated nerve closely resembles that of the normal nerve (Glees, 1943), and by the observation that the advancing axons are found almost exclusively on the inside surface of empty sheaths, referred to as Schwann tubes (Ramón y Cajal, 1928; Holmes and Young, 1942; Scherer and Easter, 1984; Scherer, 1986). These tubes, which consist of the collagenous endoneurial sheaths and basal laminae of Schwann cells (Thomas, 1964), retain their structure when the distal stump is denervated during Wallerian degeneration (Weddell, 1942). The foregoing observations have led to the idea that Schwann tubes exert a channeling influence on the axons that regenerate into them, each tube constraining

\footnotetext{
Received July 8, 1987; revised Nov. 12, 1987; accepted Nov. 13, 1987.

We thank Ms. Sibyl Bemelmans (Wray) for her expert technical assistance. This work was supported by USPHS Grant NS16030, with facilities support from USPHS Grant NS14899.

Correspondence should be addressed to P. B. Farel, Department of Physiology CB 7545, School of Medicine, University of North Carolina, Chapel Hill, NC 27599.

aPresent address: Dept. of Physiology and Biophysics, University of Iowa, Iowa City, IA 52242.

Copyright (C) 1988 Society for Neuroscience $0270-6474 / 88 / 072430-08 \$ 02.00 / 0$
}

its enclosed axons to grow only to the target located at the end of that tube (Glees, 1943). This idea is supported by the finding that reinnervation is almost always nonspecific when the tubes are disrupted by transection (Brushart and Mesulam, 1980; Mizuno et al., 1980; Westerfield and Powell, 1983), presumably because regenerating sprouts nonselectively enter the cut ends of tubes at the lesion site (Ramón y Cajal, 1928). In contrast, several instances of more specific reinnervation have been reported following nerve crush, which severs axons but leaves them surrounded by their own, appropriate Schwann sheaths (Wall et al., 1983; Wcsterficld and Powcll, 1983; Farel and Bemelmans, 1986). However, nerve crush does not always result in specific target reinnervation (Evans and Murray, 1954; Taylor et al., 1983).

The channeling effect of Schwann tubes has never been demonstrated directly, largely because the courses of individual tubes contained within the distal nerve stump are not known. In fact, regenerating axons have been reported growing outside Schwann tubes and through tube walls (Ramón y Cajal, 1928; Bennett et al., 1973; Holder et al., 1984; Krarup and Gilliatt, 1985). It remains possible that regenerating axons exhibit a preference for growth along particular structures within the distal stump but are not rigidly confined by them. Instead, the lack of specificity that typically follows peripheral nerve transection might reflect an inherent inability of mature axons to make correct pathway selections, irrespective of environmental constraints.

To test for the presence and strength of a channeling influence on regenerating axons, we have examined the pathway choices made by regenerating hindlimb motoneurons in larval and juvenile bullfrogs. The frog hindlimb is innervated by nerves that arise from a plexus formed by axons of the 3 lumbar spinal nerves. Motor axons were induced to regenerate by transecting either the lumbar ventral roots (VRs) or the spinal nerves just proximal to the plexus. In the case of VR transections, axons regrowing from each VR usually enter that root's own distal stump (see Materials and Methods). Hence, if they are confined by structures in the stump, their ultimate destinations should be limited to targets within that root's normal field of innervation. We found that the innervation field of each transected VR was nearly identical to normal. However, when the spinal nerves were transected at the level of the plexus, severing both motor and sensory axons and giving regenerating axons access to the denervated structures of other segments, motor axons failed to reestablish their normal segmental innervation fields; furthermore, some motor axons regenerated into cutaneous nerves, pathways normally limited to sensory axons. Our findings, therefore, suggest that the pathways followed by regenerating axons are strongly influenced by the structures the axons encounter as they penetrate the distal stump. 
Preliminary accounts of some of these results have appeared (Lee and Farel, 1986; Farel, 1987).

\section{Materials and Methods}

Transections of ventral roots and spinal nerves. The lumbar VRs or spinal nerves (designated 8,9 , and 10 , according to the scheme of Gaupp 1896) were transected on either the right or the left side of commercially supplied larval and juvenile bullfrogs (Rana catesheiana). Details of the surgical procedure for VR transections are described in Farel and Bemelmans (1986). To expose the spinal nerves, a small opening was made in the abdominal cavity on one side, near the base of the hindlimb. The spinal nerves could be seen through this opening and were transected just proximal to the plexus with iridectomy scissors. After surgery, the animals were maintained in plastic bins containing approximately 2 liters of dechlorinated tap water at room temperature $\left(22-26^{\circ} \mathrm{C}\right)$.

Retrograde labeling studies indicate that lumbar motoneurons nonspecifically reinnervate muscles in the hindlimb if transected after stage VIII (Farel and Bemelmans, 1986). In the present study, VR transections were performed on tadpoles at stages XI-XVIII (Taylor and Kollros, 1946), and the spinal nerves were transected in tadpoles at stages XVIIXVIII, or in juvenile frogs, depending upon seasonal availability. Therefore, this investigation examines the pathway selections made by motor axons that have not specifically reinnervated their original target muscles. For comparison, all 5 hindlimb digits are first detectable at stage $\mathrm{X}$, the forelimbs emerge from the body wall at stage $\mathrm{XX}$, and the tail is completely resorbed at stage XXV.

Physiology. Animals were selected for physiological testing after postoperative periods of 5-18 weeks. This timle interval is sufficient for extensive reinnervation of the limb (Farel and Bemelmans, 1986). Tadpoles and juvenile frogs were anesthetized on ice, then quickly decapitated and eviscerated. The dorsal surface of the spinal cord was exposed, and the spinal roots on both sides were severed close to the cord, which was then removed and discarded. On each side, a block of tissue, consisting of a hindlimb plus half of the vertebral column and axial musculature between spinal segments 7 and 11 , was isolated. Contained in the blocks were the lumbar VRs, dorsal roots, and spinal nerves, all in continuity with the hindlimb nerves. The lumbar plexus was exposed on each side and assigned to one of the 7 types described by Cruce (1974) on the basis of plexus shape and the relative sizes of the lumbar spinal nerves. Plexus types A-E, which are of concern to this study, are characterized by a progressively smaller contribution from VR 8 and progressively more from VR 10 . In experiments in which the VR innervation fields were mapped extensively, each hindlimb was dissected to expose 17 muscle nerves: 12 innervating muscles in the hip and thigh, and 5 supplying the shank and foot. The nerves were identified according to Gaupp (1896) and are illustrated schematically in Figure 1. The preparation was then pinned to the bottom of a Sylgard-lined chamber containing Ringer's solution (composition in mM: NaCl, $125, \mathrm{KCl}, 3$, $\left.\mathrm{CaCl}_{2}, 1.8, \mathrm{HEPES}, 5 ; \mathrm{pH} 7.2\right)$ maintained at approximately $10^{\circ} \mathrm{C}$ by Peltier cooling devices.

To map hindlimb innervation fields following VR transection, 3 suction electrodes recorded from VRs 8-10, while a fourth was used to stimulate the proximal cut end of each of the $17 \mathrm{limb}$ nerves with single shocks. Although these shocks elicited action potentials in sensory as well as motor axons, synaptic interactions between afferents and motoneurons were not possible in our preparations, since the spinal cord was not present. The selectivity of nerve stimulation was verified by delivering shocks of the same intensity with the stimulating electrode near, but not touching, the nerve; no action potentials were elicited under these conditions. Therefore, the occurrence of spikes in a VR in response to stimulation of a limb nerve implies that that VR contributed axons to the stimulated nerve. Inspection of the VRs during dissection occasionally revealed bundles of axons that had grown from the proximal stump of one VR to the distal stump of a VR in an adjacent segment. These bundles were severed to insure that any shock-elicited spikes in a VR must have propagated along axons that entered the segmentally appropriate distal stump and spinal nerve. Failure to cut these aberrant bundles would have blurred the distinction between VR transection and spinal nerve transection (see below).

A less extensive mapping of segmental innervation fields was performed on tadpoles with spinal nerve transections. In these animals, recordings were made only from VRs 8 and 10 , and only 6 nerves were stimulated: 3 branches of the crural nerve, 2 branches of the profundus anterior nerve, and the iliofibularis nerve.

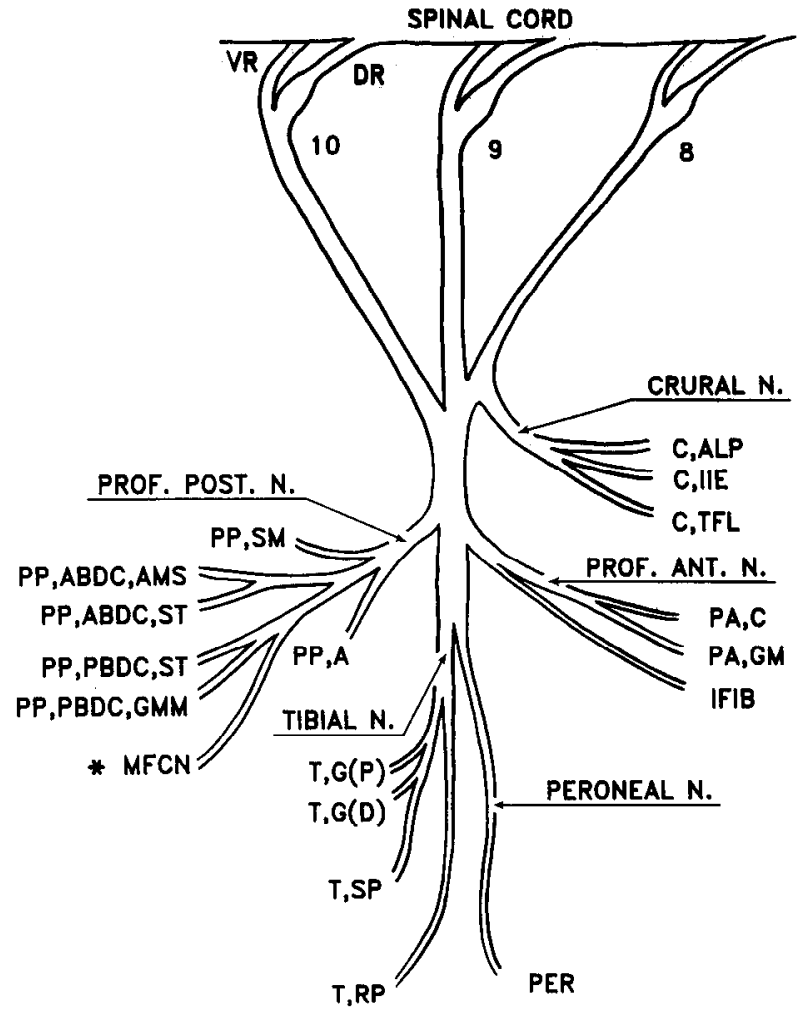

Figure 1. Schematic diagram of the preparation, showing the relative locations of the 17 muscle nerves and the single cutaneous nerve $\left(^{*}\right)$ tested for innervation by regenerating motor axons. Abbreviations used here and in subsequent figures: $V R$, ventral root; $D R$, dorsal root. Branches of the crural nerve: $C, A L P$, adductor longus and pectineus; $C, I I E$, iliacus internus and externus; $C, T F L$, tensor fasciae latae. Branches of the profundus anterior nerve: $P A, C$, cruralis; $P A, G M$, glutaeus magnus; $I F I B$, iliofibularis. Branches of the profundus posterior nerve: $P P, S M$, semimembranosus; $P P, A B D C, A M S$, anterior branch of descendens communis (innerv. adductor magnus and sartorius); $P P, A B D C, S T$, anterior branch of descendens communis (innerv. ventral head of semitendinosus); $P P, P B D C, S T$, posterior branch of descendens communis (innerv. dorsal head of semitendinosus); $P P, P B D C, G M M$, posterior branch of descendens communis (innerv, gracilis major and minor); $P P, A$, adductorius branch (innerv. adductor magnus, quadratus femoris, and obturator externus); ${ }^{*} M F C N$, medial femoral cutaneous nerve. Branches of the tibial nerve: $T, G(P)$, proximal branch to gastrocnemius; $T, G(D)$, distal branch to gastrocnemius; $T, S P$, subaponeuroticus proprius branch (innerv. various muscles in the foot); $T, R P$, ramus profundus (innerv. muscles in the toes); PER, peroneal nerve (innerv. muscles in the toes).

In experiments designed to test the ability of regenerating motor axons to discriminate between sensory and motor pathways, recordings were made from ventral and dorsal roots 8-10 while the medial femoral cutaneous nerve (MFCN) was stimulated (Fig. 1). This nerve provides sensory innervation to the skin of the posterior thigh. All of the operated animals tested in this way had received spinal nerve transections as juvenile frogs.

Electrophysiological data were digitized with a $95 \mu \mathrm{sec}$ sampling interval on a PDP Micro 11/23 + (Digital Equipment Corp.) and stored on diskette. For particular plexus types, results from the regenerated sides of operated animals were compared with data obtained from the contralateral (intact) sides of these animals and from both sides of previously unoperated animals.

1natomy. HRP (Sigma type VI) was applied to the MFCN on the operated side of 6 juvenile frogs 6-8 weeks following transection of spinal nerves 8-10. On the contralateral side, HRP was placed in the musculature of the ventral thigh as a control for the efficacy of the labeling procedure. The same sites were labeled in 4 unoperated, juvenile frogs. After 5-6 d, the spinal cords of these animals were fixed, reacted en bloc with diaminobenzidine, sectioned in paraffin, and examined for the presence of labeled motoneurons on both sides. Additional details 


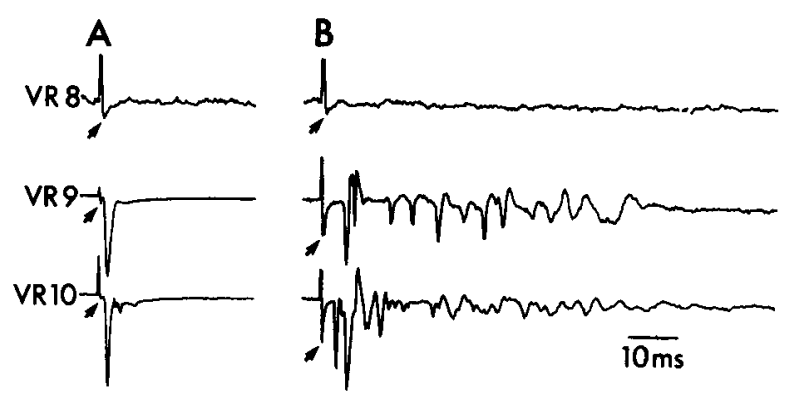

Figure 2. Recordings from the lumbar ventral roots on both sides of a tadpole during stimulation of one of the hindlimb muscle nerves. On the intact $(A)$ and regenerated $(B)$ sides, antidromic action potentials were recorded in VRs 9 and 10, but not in VR 8, when the glutaeus magnus branch of the profundus anterior nerve was shocked. Each trace is an average of 5 sweeps. Arrows mark the stimulus artifacts. The recordings were obtained from a stage 14 tadpole, $57 \mathrm{~d}$ after VR transection.

of the HRP application procedures and histological methods are described in Farel and Bemelmans (1986).

\section{Results}

Hindlimb innervation fields following ventral root transection

Figure 2 illustrates the segmental innervation pattern for one hindlimb muscle nerve on either side of an operated animal. In this example, shocking the glutaeus magnus branch of the profundus anterior nerve on either side elicited antidromic impulses in VRs 9 and 10, but not in 8 . Thus, the pattern of innervation was the same on the 2 sicies: motor axons regenerated into this nerve from segments 9 and 10 , but not from 8 , thereby reestablishing the normal innervation pattern of the nerve.

One striking feature of these recordings is the difference in the time of arrival of impulses between the 2 sides: those on the regenerated side appeared after a longer initial latency, and continued to arrive over a more prolonged period, than those on the intact side. This result was obtained consistently in our preparations. None of the impulses could have been synaptically evoked, since the shocks were delivered to a preparation from which the spinal cord had been removed. A likely explanation for the increased latency on the regenerated side is that many of the axons on that side had a lower-than-normal conduction velocity. Reduced conduction velocities are characteristic of regenerated axons, which may have small diameters, short internodal distances, and incomplete myelination (Sunderland, 1978). The impulses shown in Figure 2 would have traveled at speeds of approximately $0.2-5 \mathrm{~m} / \mathrm{sec}$ on the regenerated side and 2$11 \mathrm{~m} / \mathrm{sec}$ on the intact side.

The frequency with which VRs 8-10 innervated each of the 17 hindlimb muscle nerves shown in Figure 1 was compared in limbs ipsilateral and contralateral to the side of VR transection and in limbs on both sides of unoperated animals. In order to compensate for the variability in segmental innervation patterns that exists even in normal limbs (Cruce, 1974), comparisons were limited to limbs that fell into either of 2 categories: (1) those with a C- or D-type lumbar plexus (Cruce, 1974), in which axons are supplied to the plexus in equal numbers by spinal nerves 9 and 10 , and in lesser numbers by 8 ; and (2) limbs with an A-type plexus, in which axons are supplied in equal numbers by 8 and 9 , and in lesser numbers by 10 . Limbs with other plexus types were encountered too infrequently to permit comparison.
The segmental innervation patterns for all 17 hindlimb nerves in limbs with C- and D-type plexuses are shown in Figure 3. The innervation patterns of nerves on the intact sides of operated animals were very similar to those obtained in normal, unoperated animals. Therefore, results from these 2 groups are combined in Figure 3 for comparison with the regenerated group. Figure 4 compares the VR innervation fields in limbs with the rarer A-type plexus. The graphs in Figures 3 and 4 demonstrate that, for all 3 VRs, the hindlimb innervation fields of the regenerated axons closely resembled those that exist normally. This similarity even extends down to the level of particular branches of the major limb nerves. For example, in limbs with C- and D-type plexuses (Fig. 3), VR 9 innervated the gastrocnemius muscle normally and after regeneration, and the frequency with which it provided axons to the 2 branches supplying this muscle varied in the sarie way in both groups: the distal branch [T,G(D)] was always innervated by VR 9, while the proximal branch $[T, G(P)]$ was innervated by VR 9 in only about half of the limbs with this plexus type. The distribution of axons from VR 8 into the 3 divisions of the crural nerve (Fig. 3) further illustrates this point.

The major differences between the hindlimb innervation fields of normal and regenerated axons occurred in nerves thac were supplied less frequently by a particular VR after regeneration (e.g., VR 10's innervation of PP,PPDC,GMM; Fig. 4). There are several possible reasons why regenerated axons from one VR may not have been found in a nerve that is normally within that VR's field of innervation. First, regrowing axons occasionally grew into the distal stumps of VRs in adjacent segments; these errant axons were cut prior to testing (see Materials and Methods). Second, the axons might have grown into other nerves within the VR's innervation field, leaving some nerves uninnervated by that VR. Third, some of the regenerated axons may have been severed accidentally during dissection of the often fragile transection site.

Although the innervation fields of regenerated axons may be smaller than normal in some limbs, they are still contained within the normal fields. Therefore, for both categories of plexus, the results indicate that axons regenerating from a transected VR rarely, if ever, grow beyond the territory normally supplied by that VR.

\section{Hindlimb innervation fields following spinal nerve transection}

The reestablishment of ncarly normal scgmental innervation fields by these regenerating axons is consistent with the hypothesis that the axons were channeled to their destinations by preexisting structures within each distal nerve stump. Alternatively, such innervation patterns might reflect an ability on the part of the axons to recognize segmentally appropriate growth pathways, even though the axons appear to be incapable of selectively reinnervating their original muscles (Farel and Bemelmans, 1986).

To distinguish between these possibilities, the 3 lumbar spinal nerves were transected on one side at the point where they converge to form the hindlimb plexus in 5 tadpoles with $\mathrm{C}$ - and D-type plexuses. This more distal transection provides the regenerating axons with roughly equal access to the denervated nerve stumps of all 3 spinal segments. Six weeks later, the innervation fields of motor axons from VRs 8 and 10 were determined. Six of the 17 muscle nerves illustrated in Figurc 1 were tested for segmental input: the iliofibularis nerve and the 

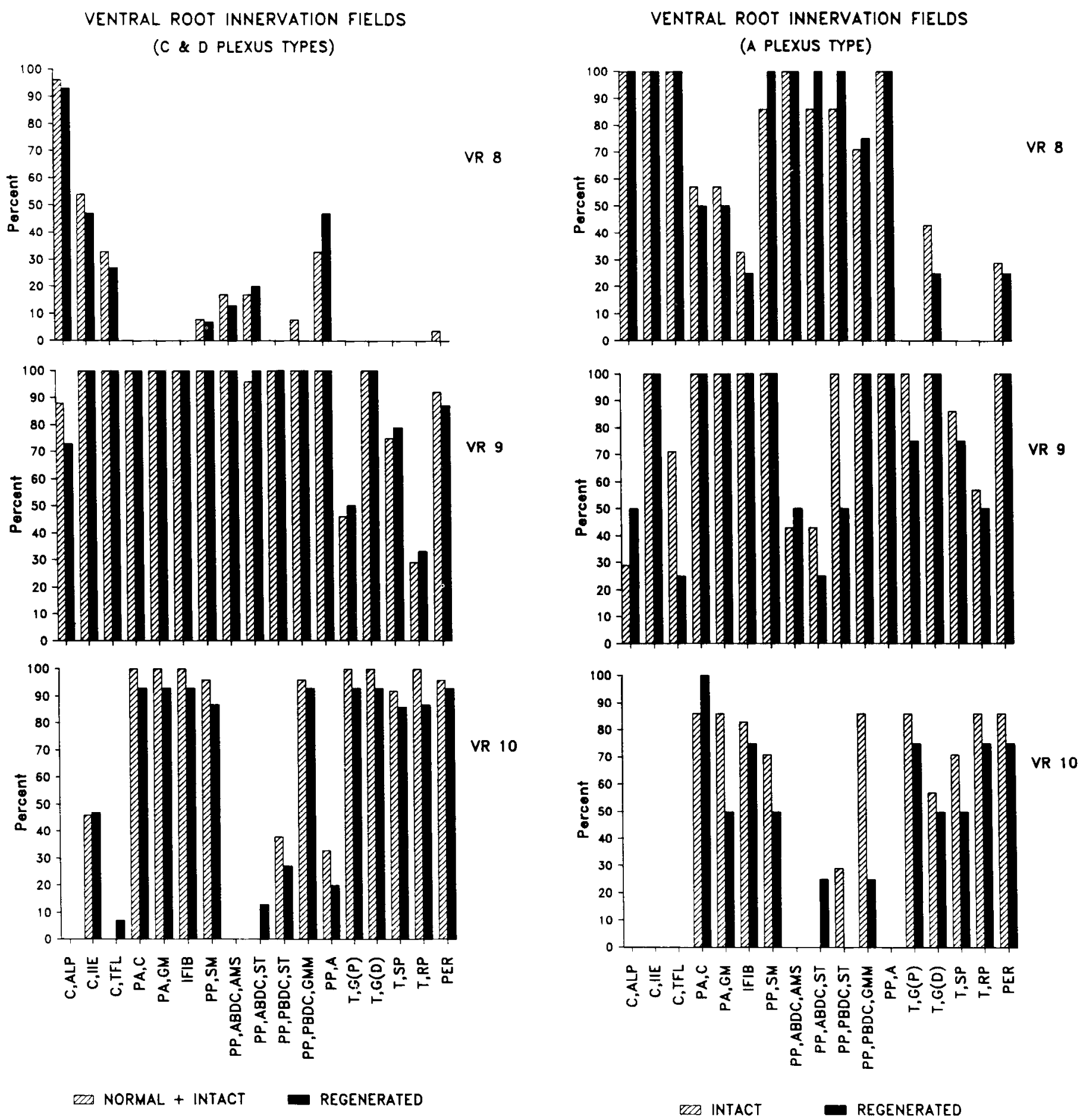

Figure 3. Segmental innervation of muscle nerves in hindlimbs with $\mathrm{C}$ and D plexus types, normally and following VR transection. The graphs in this and Figures 4 and 5 show the percentage of limbs in which each nerve was innervated by each VR. Normal + intact, each nerve was sampled in 24 limbs ( 10 from normal, unoperated animals +14 from intact, contralateral sides of operated animals). Regenerated, each nerve was sampled in 15 reinnervated limbs [except T,G(P), T,G(D), and T,SP, where $n=14]$. Note the similarity in the innervation patterns formed by normal and regenerated axons.

various branches of the crural and profundus anterior nerves. Four limbs from 2 unoperated tadpoles were examined in the same way.

The results of these experiments are shown in Figure 5. As

Figure 4. Segmental innervation of muscle nerves in hindlimbs with an A plexus type, normally and following VR transection. Intact, each nerve was sampled in 7 limbs from intact, contralateral sides of operated animals (except IFIB, where $n=6$ ). Regenerated, each nerve was sampled in 4 reinnervated limbs. As in animals with C/D-type plexuses (Fig. 3), innervation patterns formed by normal and regenerated axons are similar.

in Figure 3, the data obtained from the unoperated animals and from the intact sides of the operated animals were similar and have been combined. Motor axons regenerating from spinal nerve 8 were found only in the crural nerve branches, reestablishing the normal innervation pattern for that spinal segment. However, axons from spinal nerve 10 were found in all $6 \mathrm{limb}$ 


\section{VENTRAL ROOT INNERVATION FIELDS}
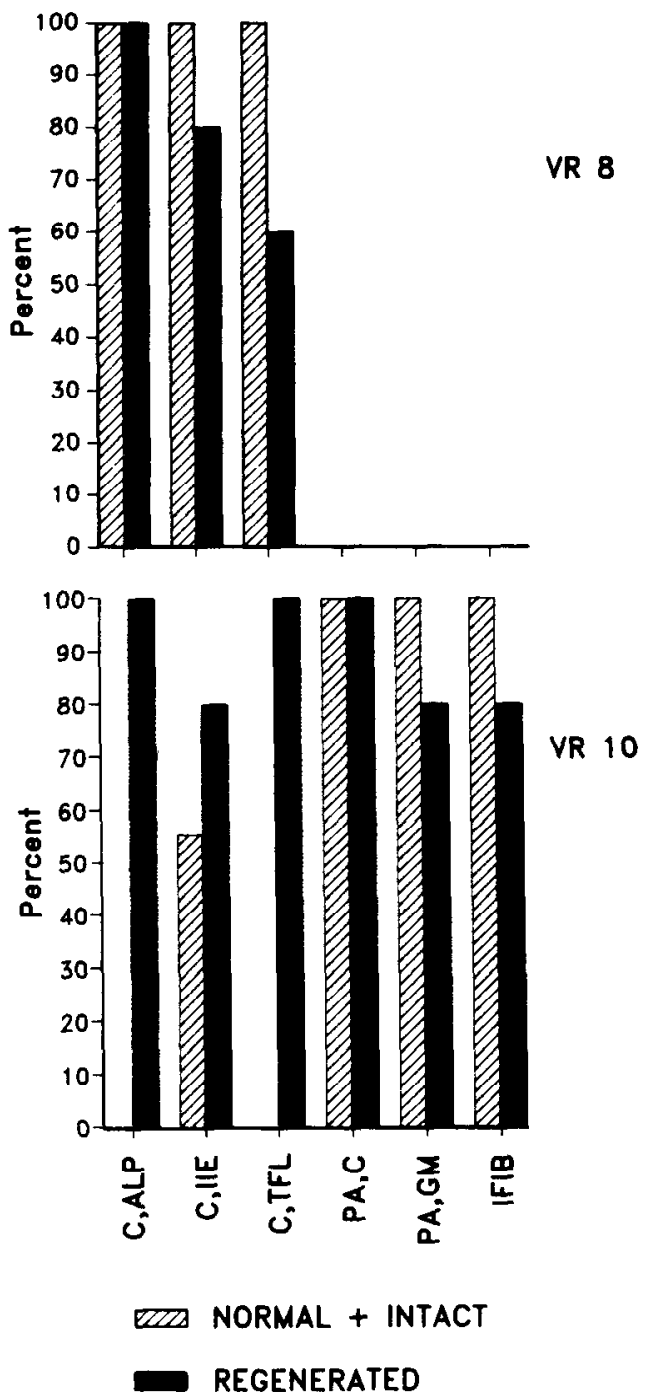

Figure 5. Segmental innervation of muscle nerves, normally and following spinal nerve transection. Normal + intact, each nerve was sampled in 9 limbs (4 from normal, unoperated animals +5 from intact, contralateral sides of operated animals). Regenerated, each nerve was sampled in 5 reinnervated limbs. In all limbs, the plexus was of the $C$ or D type. Note that, unlike the situation following VR transcetion (Figs. 3,4 ), motor axons have regenerated into motor nerves where they are not normally found, i.e., VR 10 axons are found in all 3 branches of the crural nerve following regeneration.

nerves, including 2 crural nerve branches that were never innervated by VR 10 in normal limbs. Thus, spinal nerve 10 's axons did not maintain their normal segmental boundaries during regeneration. These findings, therefore, suggest that, for at least some of the regenerating motor axons in this system, thc reappearance of a normal hindlimb innervation pattern following VR transection does not result from an active selection of growth pathways on the basis of segmental cues.

\section{Regeneration of motor axons along a sensory pathway}

To determine whether regenerating motor axons might be capable of discriminating between sensory and motor pathways, we examined one of the cutaneous nerves of the hindlimb for the presence of motor axons following spinal nerve transection.

$$
\text { Dorsal Left Side Ventrar }
$$
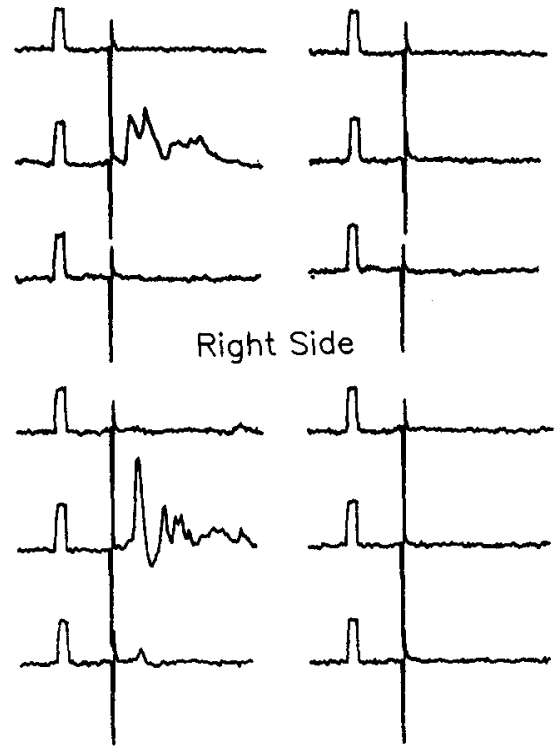

Figure 6. Recordings from the lumbar dorsal and ventral roots on the left $(t o p)$ and right (bottom) sides of a normal juvenile frog during stimulation of the medial femoral cutaneous nerve (MFCN). Segments 8, 9, and 10 are shown from top to bottom for each side. Note the consistent lack of antidromic spikes in the ventral roots. Calibration pulse, 100 $\mu \mathrm{V}, 1 \mathrm{msec}$.

Spinal nerves 8-10 were cut immediately proximal to the plexus on one side of 6 juvenile frogs. Since these transections severed both sensory and motor axons, they denervated cutaneous, as well as muscle, nerves. On the 6 contralateral, intact sides, and on 23 sides of 13 normal, unoperated frogs, stimulation of the MFCN never elicited antidromic impulses in any of the lumbar VRs, although axons in the dorsal roots of those segments were fired (Figs. 6; 7, top). In contrast, on 5 of 6 regenerated sides, antidromic spikes could be recorded in one or more VRs when the MFCN was stimulated (Fig. 7, bottom). The amplitude of these VR spikes was comparable to that of spikes in the dorsal roots, indicating that large numbers of motor axons had regenerated into what is normally a purely sensory nerve.

These findings were corroborated by anatomical studies in which HRP was applied to the MFCN on the side of spinal nerve transection in 6 other frogs, and on one side in 4 unoperated frogs. In both sets of animals, HRP was also applied to muscles of the ventral thigh on the side contralateral to the MFCN application to control for possible variabilities in the sensitivity of HRP processing. All of the operated and unoperated animals had labeled motoneurons on the side of the spinal cord where the muscles had been injected. In addition, 3 of the 6 frogs with previously transected spinal nerves had labeled motoneurons on the operated side, where the MFCN had been labeled (Fig. 8). No labeled motoneurons were found on that side in any of the unoperated frogs. Hence, regenerating motor axons do not distinguish between sensory and motor pathways when given an equal opportunity to enter both.

\section{Discussion}

Our results demonstrate that bullfrog motoneurons regenerating from a transected VR reinnervate a region of the hindlimb that is restricted to the normal inncrvation ficld of that VR. In these 


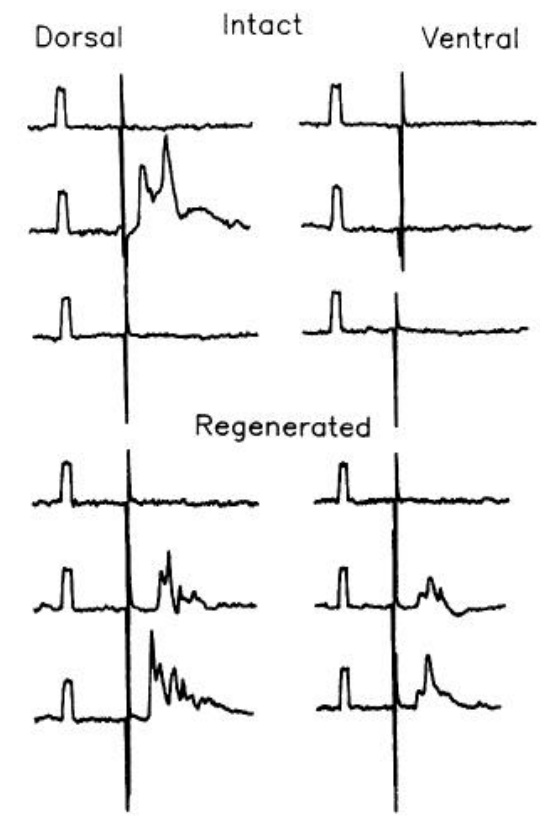

Figure 7. Recordings from the lumbar dorsal and ventral roots on the intact (top) and regenerated (bottom) sides of a juvenile frog during stimulation of the MFCN. The lumbar spinal nerves had been transected on one side $62 \mathrm{~d}$ earlier. Segments 8,9 , and 10 are shown from top to bottom for each side. Note that stimulation of the MCFN activates VR fibers only on the regenerated side. Calibration pulse, $100 \mu \mathrm{V}, 1 \mathrm{msec}$. This result provides physiological evidence that motor axons regenerate into pathways that, in unoperated animals, contain only sensory axons.

experiments, the original, prelesion innervation field for each VR was inferred from tests on limbs with an intact nerve supply and the same type of plexus. We assume that the plexus type on each regenerated side did not change during the time between VR transection and physiological testing. This is likely a safe assumption, considering the stability of structures in distal nerve stumps (Weddell, 1942; Glees, 1943) and the fact that plexus morphology is determined in part by sensory axons that are not disrupted by VR transection.

Farel and Bemelmans (1986) showed that bullfrog motoneurons do not specifically reinnervate their original target muscles in the hindlimb when axotomized at the developmental stages used in our experiments. In light of those results, it may seem paradoxical that normal VR innervation fields are reestablished after regeneration. The explanation for these apparently discordant results lies in the manner in which hindlimb reinnervation was assessed in the 2 investigations. In the earlier study, HRP was applied to one of 3 sites in the limb, and the locations of retrogradely labeled motoneuronal somata were mapped for each site, without determining which VRs contained the labeled cells' axons. The distribution of labeled somata after regeneration was found to be more widespread than normal, indicating that some motoneurons had regrown to inappropriate sites in the limb. The present experiments were designed to ascertain whether motor axons that had regenerated along the distal stump of a particular VR could grow into limb nerves not normally supplied by that VR. Since the axons in each VR project to a variety of muscles in different regions of the limb (see Figs. 3, 4), it is possible for axons regenerating from a particular VR to make major projection errors at the level of individual muscles, while remaining within the normal innervation field of that VR.

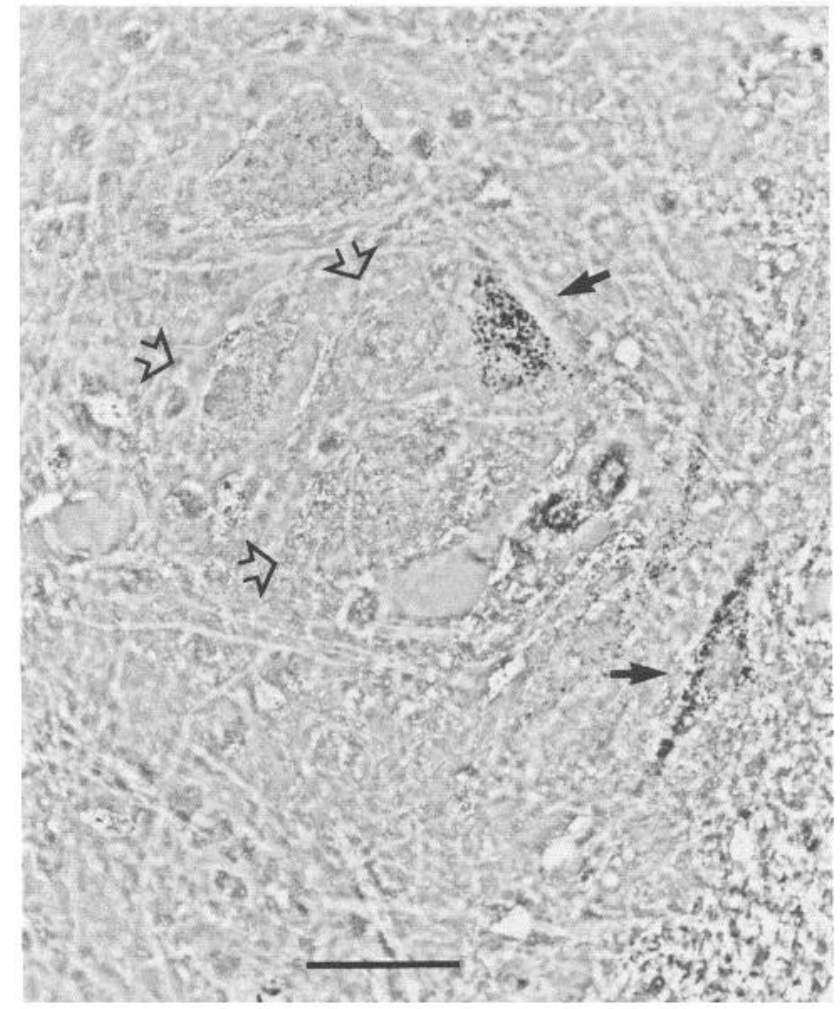

Figure 8. Phase-contrast photomicrograph of motoneurons retrogradely labeled by HRP application to the ipsilateral MFCN in a juvenile frog $44 \mathrm{~d}$ following spinal nerve transection. Motoneurons were never labeled from this nerve in unoperated frogs. Closed arrows indicate HRP-labeled motoneurons. Open arrows point to adjacent, unlabeled motoneurons. Calibration bar, $40 \mu \mathrm{m}$. This result provides anatomical evidence that motor axons regenerate into pathways that, in unoperated animals, contain only sensory axons.

Hence, nonspecific target reinnervation can be compatible with the maintenance of normal segmental innervation patterns.

Although regenerating motor axons do not show a preference for their original targets during reinnervation of the hindlimb, it remains possible that they reestablished their normal segmental fields because of an ability to discriminate among pathways on the basis of segmental cues. Regenerating preganglionic axons in the mammalian autonomic nervous system exhibit segmental selectivity during reinnervation of superior cervical ganglion neurons (Langley, 1897; Njå and Purves, 1977). Furthermore, when preganglionic axons are forced to grow into transplanted intercostal muscles, they innervate those inappropriate targets in a manner that is segmentally specific (Wigston and Sanes, 1985). We found that motor axons from spinal segment 8 reformed an apparently normal hindlimb innervation pattern even when transected near the plexus. However, the geometry of the plexus is such that VR 8 typically merges with VR 9 somewhat proximal to the anastomosis of VRs 9 and 10. Consequently, it is not clear whether axons from the proximal stump of VR 8 had access to pathways normally occupied by VR 10 axons. Our finding that motor axons from segment 10 ignore segmental boundaries when regenerating after spinal nerve transection argues against the notion that growth patterns result from an active selection of segmentally approporiate pathways. Instead, our results support the hypothesis that the elongation of frog motor axons is constrained by the structures the axons enter as they penetrate the distal nerve stump. 
One candidate for such structures are the acellular Schwann (endoneurial) tubes which remain in the distal stump when the axons degenerate (Weddell, 1942). The remarkable affinity of growth cones for the inner surface of endoneurial basal laminae (Ide, 1983). increases the probability that an axon will follow a Schwann tube's course once it enters the tube and contacts its basal lamina. However, the reported ability of regenerating axons to deviate from the paths of Schwann tubes (see the introduction) argues against the idea that the axons are truly confined by these structures. If axons have the capacity to escape from and re-enter Schwann tubes anywhere along their length, the axons' lower affinity for the substrate outside the tubes would dictate that any transitions between tubes will be short compared to the distance traveled inside any individual tube. This prediction is consistent with the infrequency with which extratubal sprouts can be detected in regenerated nerves (Ramón y Cajal, 1928; Scherer and Easter, 1984).

Alternatively, guidance of axons regenerating in the peripheral nervous system might be provided, to some extent, by both Schwann tubes and the perineurium, a sheath composed of several layers of flattened cells connected by tight junctions (Thomas and Olsson, 1975). While some smaller nerves are ensheathed by a single perineurium (e.g., the trochlear nerve in goldfish; Scherer and Easter, 1984), larger nerve trunks may contain a number of perineuria, each of which surrounds a bundle of axons (Sunderland, 1978). Two lines of evidence suggest that surviving perineurial sheaths may play a role in guiding regenerating axons. First, unlike the endoneurium, in mature nerves the perineurium is relatively impervious even to diffusible substances, owing to the tight junctions between its cells (Sunderland, 1978). The diffusion barrier of the perineurium is not fully formed in immature animals (Hansson et al., 1971; Kristensson and Olsson, 1971), which may explain why motoneurons specifically reinnervate the tadpole hindlimb only when transected during early stages of development (Farel and Bemelmans, 1986). Second, when a muscle is partially denervated, nodal sprouts from intact motor axons can leave the endoneurial tube of their parent axon to extend along a vacated nerve branch within the same perineurial sheath (Slack et al., 1979; Angaut-Petit et al., 1982).

It has recently been reported that the levels of NGF and its mRNA increase in the distal stump of rat peripheral nerve within a few days of nerve transection (Korsching et al., 1986), and that all Schwann cells in the stump markedly increase their expression of low-affinity NGF receptors during this period (Taniuchi et al., 1986). Taniuchi et al. (1986) propose that NGF binds to cell-surface receptors of denervated Schwann cells and is subsequently transferred to the NGF receptors of regenerating axons. By this means, Schwann cells could provide both trophic support and tropic guidance to regenerating axons of NGFsensitive neurons, and, by expression of as-yet-unidentified agents, to axons of other neurons as well. However, the lack of target specificity by regenerating frog motoneurons (Farcl and Bemelmans, 1986) and the inability of sensory axons to selectively innervate cutaneous nerves (see also Watrous, 1940; Inberg, 1949) show that these mechanisms, if they indeed operate in frog, are insufficient to significantly influence axon guidance during regeneration.

Our results, therefore, indicate that regenerating motor axons in frogs and advanced tadpoles do not discriminate among pathways on the basis of the muscles they lead to, the segmental labels they may possess, or the fact that they normally exclude motor axons in favor of sensory axons. The question of whether regenerating axons could discriminate among pathways were they not constrained by physical structures of the distal stump remains unanswered.

The observation that regenerating motor axons in mature frogs can selectively reinnervate twitch versus tonic fibers in the same muscle (Elizalde et al., 1983) suggests that these axons are capable of some selectivity in synapse formation. If regenerating axons are able to grow freely only in close proximity to their target muscles, the relatively large distances separating muscles in limbs of mature animals may make it impossible for the axons to express any intermuscular selectivity they may possess (Wigston, 1985; Wigston and Sanes, 1985). Hence, we cannot rule out the possibility that these rcgenerating axons could distinguish appropriate from inappropriate targets if given unimpeded access to both at close range.

\section{References}

Angaut-Petit, D., A. Mallart, and L. Faille (1982) Role of denervated sheaths and end-plates in muscle reinnervation by collateral sprouting in mouse. Biol. Cell 46: 277-289.

Bennett, M. R., E. M. McLachlan, and R. S. Taylor (1973) The formation of synapses in reinnervated mammalian striated muscle. $J$. Physiol. (Lond.) 233: 481-500.

Brushart, T. M., and M.-M. Mesulam (1980) Alteration in connections between muscle and anterior horn motoneurons after peripheral nerve repair. Science 208: 603-605.

Cruce, W. L. R. (1974) The anatomical organization of hindlimb motoneurons in the lumbar spinal cord of the frog, Rana catesbiana. J. Comp. Neurol. 153: 59-76.

Elizalde, A., M. Huerta, and E. Stefani (1983) Selective reinnervation of twitch and tonic muscle fibres of the frog. J. Physiol. (Lond.) 340 : 513-524.

Evans, D. H. L., and J. G. Murray (1954) Regeneration of non-medullated nerve fibres. J. Anat. 88: 465-480.

Farel, P. B. (1987) Regeneration of spinal motor axons into cutaneous sensory pathways. Soc. Neurosci. Abstr. 13:1210.

Farel, P. B., and S. E. Bemelmans (1986) Restoration of neuromuscular specificity following ventral rhizotomy in the bullfrog tadpole, Rana catesbeiana. J. Comp. Neurol. 254: 125-132.

Gaupp, E. (1896) A. Ecker's und R. Wiedersheim's Anatomie des Frosches, Vieweg, Braunschweig.

Glees, P. (1943) Observations on the structure of the connective tissue sheaths of cutaneous nerves. J. Anat. 77: 153-159.

Hansson, G., K. Kristensson, Y. Olsson, and J. Sjöstrand (1971) Embryonal and postnatal development of mast cells in rat peripheral nerve. Acta Neuropathol. (Berl.) 17: 139-149.

Holder, N., D. A. Tonge, and P. Jesani (1984) Directed regrowth of axons from a misrouted nerve to their correct muscles in the limb of the adult newt. Proc. R. Soc. Lond. [Biol.] 222: 477-489.

Holmes, W., and J. Z. Young (1942) Nerve regeneration after immediate and delayed suture. J. Anat. 77: 63-96.

Ide, C. (1983) Nerve regeneration and Schwann cell basal lamina: Observations of the long-term regeneration. Arch. Histol. Japon. 46: 243-257.

Inberg, K. R. (1949) Regeneration of the motor and sensory fibres in the sciatic nerve and the suralis nerve of the cat. Acta Physiol. Scand. 18: 308-323.

Korsching, S. I., R. Heumann, A. Davies, and H. Thoenen (1986) Levels of nerve growth factor and its mRNA during development and regeneration of the peripheral nervous system. Soc. Neurosci. Abstr. 12: 1096.

Krarup, C., and R. W. Gilliatt (1985) Some effects of prolonged constriction on nerve regeneration in the rabbit. J. Neurol. Sci. 68: 114.

Kristensson, K., and Y. Olsson (1971) The perineurium as a diffusion barrier to protein tracers: Differences between mature and immature animals. Acta Neuropathol. (Berl.) 17: 127-138.

Langley, J. N. (1897) On the regeneration of pre-ganglionic and postganglionic visceral nerve fibers. J. Physiol. (Lond.) 22: 215-230.

Lee, M. T., and P. B. Farel (1986) Guidance of regenerating bullfrog motor axons. Soc. Neurosci. Abstr. 12: 1504. 
Mizuno, N., M. Uemura-Sumi, K. Matsuda, Y. Takeuchi, M, Kume, and R. Matsushima (1980) Non-selective distribution of hypoglossal nerve fibers after section and resuture: A horseradish peroxidase study in the cat. Neurosci. Lett. 19: 33-37.

Njå, A., and D. Purves (1977) Reinnervation of guinea pig superior cervical ganglion cells by preganglionic fibres arising from different lcvels of the spinal cord. J. Physiol. (Lond.) 272: 633-651.

Ramón y Cajal, S. (1928) Degeneration and Regeneration of the Nervous System, R. M. May, ed. and trans., Hafner, New York.

Scherer, S. S. (1986) Reinnervation of the extraocular muscles in goldfish is nonselective. J. Neurosci. 6: 764-773.

Scherer, S. S., and S. S. Easter, Jr. (1984) Degenerative and regenerative changes in the trochlear nerve of goldfish. J. Neurocytol. 13: 519-565.

Slack J. R., W. G. Hopkins, and M. N. Williams (1979) Nerve sheaths and motoneurone collateral sprouting. Nature 282: 506-507.

Sunderland, S. (1978) Nerves and Nerve Injuries. Churchill Livingstone, New York

Taniuchi, M., H. B. Clark, and E. M. Johnson, Jr. (1986) Induction of nerve growth factor receptor in Schwann cells after axotomy. Proc. Natl. Acad. Sci. USA 83: 4094-4098.

Taylor, A. C., and J. J. Kollros (1946) Stages in the normal development of Rana pipiens larvae. Anat. Rec. 94: 7-23.

Taylor, B., T. E. Finger, G. D'Arcy, and S. D. Roper (1983) Accuracy of regeneration of vagal parasympathetic axons. J. Comp. Neurol. 221: $145-153$

Thomas, P. K. (1964) Changes in the endoneurial sheaths of peripheral myelinated nerve fibres during Wallerian degeneration. J. Anat. 98: $175-182$

Thomas, P. K., and Y. Olsson (1975) Microscopic anatomy and function of the connective tissuc components of peripheral ncrve. In $\mathrm{Pe}$ ripheral Neuropathy, P. J. Dyck, P. K. Thomas, and E. H. Lambert, eds., pp. 168-189, Saunders, Philadelphia, PA.

Wall, J. T., D. J. Felleman, and J. H. Kaas (1983) Recovery of normal topography in the somatosensory cortex of monkeys after nerve crush and regeneration. Science 221: 771-773.

Watrous, W. G. (1940) Axon branching after nerve regeneration. Proc. Soc. Exp. Biol. Med. 44: 541-542.

Weddell, G. (1942) Axonal regeneration in cutaneous nerve plexuses. J. Anat. 77: 49-62.

Westerfield, M., and S. L. Powell (1983) Selective reinnervation of limb muscles by regenerating frog motor axons. Dev. Brain Res. 10: 301-304.

Wigston, D. J. (1985) Selective reinnervation of axolotl limb muscles. Soc. Neurosci. Abstr. 11: 976.

Wigston, D. J., and J. R. Sanes (1985) Selective reinnervation of intercostal muscles transplanted from different segmental levels to a common site. J. Neurosci. 5: 1208-1221. 